ASTHMA

\title{
Can a self-management programme delivered by a community pharmacist improve asthma control? A randomised trial
}

\author{
D Barbanel, S Eldridge, C Griffiths
}

Thorax 2003;58:851-854

See end of article for authors' affiliations

....................

Correspondence to: C Griffiths, Institute of Community Health

Sciences, Barts and the

London, Queen Mary's

School of Medicine and

Dentistry, Mile End,

London E1 4NS, UK

c.j.griffiths@qmul.ac.uk

Revised version received 28 February 2003

Accepted for publication

5 June 2003
Background: No randomised studies have addressed whether self-management for asthma can be successfully delivered by community pharmacists. Most randomised trials of asthma self-management have recruited participants from secondary care; there is uncertainty regarding its effectiveness in primary care. A randomised controlled study was undertaken to determine whether a community pharmacist could improve asthma control using self-management advice for individuals recruited during attendance at a community pharmacy.

Methods: Twenty four adults attending a community pharmacy in Tower Hamlets, east London for routine asthma medication were randomised into two groups: the intervention group received self-management advice from the pharmacist with weekly telephone follow up for 3 months and the control group received no input from the pharmacist. Participants self-completed the North of England asthma symptom scale at baseline and 3 months later.

Results: The groups were well matched at baseline for demographic characteristics and mean (SD) symptom scores (26.3 (4.8) and 27.8 (3.7) in the intervention and control groups, respectively). Symptom scores improved in the intervention group and marginally worsened in the control group to 20.3 (4.2) and 28.1 (3.5), respectively ( $p<0.001$; difference adjusted for baseline scores $=7.0$ (95\% $\mathrm{Cl} 4.4$ to 9.5 ). Conclusions: A self-management programme delivered by a community pharmacist can improve asthma control in individuals recruited at a community pharmacy. Further studies should attempt to confirm these findings using larger samples and a wider range of outcome measures.
M uch of the evidence for the effectiveness of selfmanagement programmes for asthma derives from trials recruiting participants from secondary care using programmes delivered in secondary care. ${ }^{1}$ The evidence review for the recent SIGN/BTS guidelines for asthma management highlighted two important gaps in knowledge relating to asthma self-management: (1) the effectiveness of programmes delivered by community pharmacists, and (2) programmes delivered in primary care. ${ }^{2}$

Community pharmacists have expanded their role in recent years to include giving health care advice for people with acute and chronic illness. ${ }^{3}$ This development has important implications for the organisation of care, but randomised trials testing the extended role of pharmacists are rare. No randomised studies have tested the effectiveness of asthma self-management delivered by community pharmacists.

Self-management advice for asthma is extensively promoted in primary care, but there is surprisingly little evidence about its effectiveness in this setting. Although studies have compared different ways of delivering self-care, ${ }^{4}$ to our knowledge only one study supports the view that selfmanagement advice can improve asthma control in individuals recruited in primary care, ${ }^{5}$ with others either equivocal ${ }^{6-8}$ or negative. ${ }^{910}$ Indeed, particular difficulties in delivering self-management advice for asthma in primary care include acceptability to patients and clinicians, ${ }^{11}$ as well as the milder nature of many patients' symptoms when compared with those of patients recruited from secondary care.

A study was undertaken to test whether a community pharmacist with basic asthma training could improve asthma control with a simple programme of self-management advice. The study was set in Tower Hamlets, east London, an inner city area with high asthma morbidity, an ethnically mixed population, high health care use, ${ }^{12}$ and variable delivery of primary care. ${ }^{13}$

\section{METHODS}

\section{Participants}

The pharmacist identified 25 adults with a general practitioner diagnosis of asthma who regularly visited the pharmacy for collection of prescribed medication. Participants were aged 18-65 years and were using inhaled corticosteroids. Those who had recently attended secondary care with acute asthma, who had changed asthma treatment in the last 6 weeks, or who had an acute respiratory infection were excluded. One moved away before the study started, leaving 24 participants.

After obtaining written informed consent, participants were asked to complete a baseline questionnaire giving basic information on sex, smoking status, and fluency in English. They were then randomised using sealed envelopes to intervention or control groups.

\section{Asthma symptoms questionnaire}

The outcome measure used in the study was asthma symptoms. These were measured using the North of England asthma symptoms scale, a validated instrument which measures asthma related health status and consists of 10 questions, each with five response options. ${ }^{14}$ The 10 questions address different aspects of asthma symptoms such as breathlessness, coughing, disturbed sleep and fear; each is given equal weighting and there are no separate domains. The scale is specifically designed for use in ambulatory care and has been used in randomised trials, ${ }^{15}$ epidemiological ${ }^{16}$ and observational studies. ${ }^{17}$ It is quick to complete, has excellent internal reliability (Cronbach's $\alpha=0.93$ ), and good 
validity. It is sensitive to change. ${ }^{14}$ During validation studies a 6 point reduction in score was observed in those who considered their asthma to be much improved over a 3 month period.

When completing the questionnaire during the trial, the pharmacist ensured participants understood how to complete the first question, after which participants completed the questionnaire unassisted.

\section{Intervention}

The pharmacist acting as the study intervention attended a 3 day multidisciplinary course on asthma care at the London Chest Hospital. This included discussion of self-management programmes.

Participants randomised to the intervention group received a review of their inhaler technique and personal education from the pharmacist addressing the following topics:

- Basic pathophysiology of asthma

- Recognition and avoidance of triggers

- Inhaler technique

- Self-management skills, including monitoring of peak flow or symptoms

- Action in response to worsening symptoms

- How to access emergency care appropriately

- Smoking cessation, if relevant

The individual education sessions lasted 45-60 minutes. The pharmacy had a consultation area which lacked privacy and was often noisy. For five participants the session took place within this area; for the remainder the pharmacist was able to use a room at the patients' general practitioner surgery (the general practitioner had no input into these consultations). Literature used included written personalised credit card self-management plans (Astra Laboratories) and educational leaflets ("Confidence with Asthma" and "Regular Therapy for Asthma" by GlaxoWellcome). Selfmanagement decision making was based on peak expiratory flow readings (PEFR) if the participant could use and interpret readings from a peak flow meter; otherwise, advice was based on symptoms. For self-management plans the instructions were for patients to:

- double their inhaled corticosteroid dose if their PEFR was $70-80 \%$ of best or they were waking at night with symptoms;

- contact their doctor to arrange a course of oral corticosteroid treatment if their PEFR was $50-70 \%$ or breathlessness was increasing;

- call their doctor urgently if their PEFR was below 50\% of best or if symptoms continued to worsen.

Medication was left unaltered with respect to drugs and baseline dosages prescribed; instructions focused on changing medication dosage in the face of changing symptoms or PEFR.

Intervention participants were telephoned weekly by the pharmacist and encouraged to return to the pharmacy with any problems. This contact continued for 3 months. Participants in the control group received no input from the pharmacist.

Three months after intervention all participants reattended and were asked once more to complete the North of England symptoms questionnaire. Questionnaires were completed without input from the pharmacist. Data were entered onto a database and analysed with STATA, using an analysis of covariance with the 3 month symptom score as dependent variable and baseline score as covariate.

\section{RESULTS}

Twenty four subjects were included in the study and were randomised to intervention or control groups. Groups were well matched at baseline and reflected the characteristics of the local population (table 1 ).

One participant in the control group moved away and could not be contacted for follow up data, leaving data on all 12 in the intervention group and 11 in the control group.

Baseline scores were similar in the intervention and control groups (26.3 (4.8) v 27.8 (3.7), fig 1). After 3 months all but one participant in the intervention group reported an improvement in symptoms (20.3 (4.2), mean improvement $=6$ ); the remaining participant's score was unchanged. Scores for participants in the control group worsened slightly overall to 28.1 (3.5). The improvement in mean scores in the intervention group was significant (difference adjusted for baseline scores $=7.0(95 \%$ CI 4.4 to 9.5$)$ p $<0.001$, fig 1). A sensitivity analysis showed that, even if it was assumed that the participant from the control group who had moved away improved by the mean improvement seen in the intervention group, the difference between groups remained significant.

\section{DISCUSSION}

This study suggests that a community pharmacist with basic training in asthma care can deliver a simple educational programme resulting in improvements in asthma control. To our knowledge this is the first randomised study to demonstrate the success of asthma self-management advice in the setting of a community pharmacy.

Other controlled but non-randomised data from the Danish Therapeutics Outcome Monitoring (TOM) study suggest that community pharmacists acting as part of a large multidisciplinary intervention can improve asthma outcomes. ${ }^{18}$ Other than size and randomisation, our study differed from the TOM study in two ways: we did not change dosages of asthma medication and our intervention was simple, focusing on self-management advice rather than the TOM system which comprised a complex package of "a patient care process, clinical record system, educational materials for pharmacists and patients, and descriptive material for patients and physicians". This is important for two reasons. Firstly, the benefits seen in our study are likely to accrue from behaviour change rather than optimisation of medication regimens at entry to the study. Secondly, our package of care could be delivered by any community pharmacist with an interest in asthma, basic training in asthma management, and a reasonably private area in which to consult.

The study also adds weight to the view that self-management advice can be effective in primary care. To date, only one randomised study has shown benefit of self-management advice in patients recruited in general practice. ${ }^{5}$ The educational intervention in this case was delivered by a specialist chest physician. Other studies have been equivocal

\begin{tabular}{lll}
$\begin{array}{l}\text { Table } 1 \text { Characteristics of study participants at } \\
\text { randomisation }\end{array}$ & Intervention $(\mathbf{n}=12)$ & Control $(\mathbf{n}=12)$ \\
\hline & $6 / 6$ & $5 / 7$ \\
$M / F$ & $45(17)$ & $47(17)$ \\
Mean (SD) age (years) & 5 & 6 \\
Smoker & 5 & 3 \\
Non-smoker & 1 & 1 \\
Ex-smoker & 1 & 2 \\
Passive smoker & 4 & 3 \\
Ethnic minority group & 11 & 11 \\
Understands English & 2 & 0 \\
Needs interpreter & & \\
\hline
\end{tabular}


A

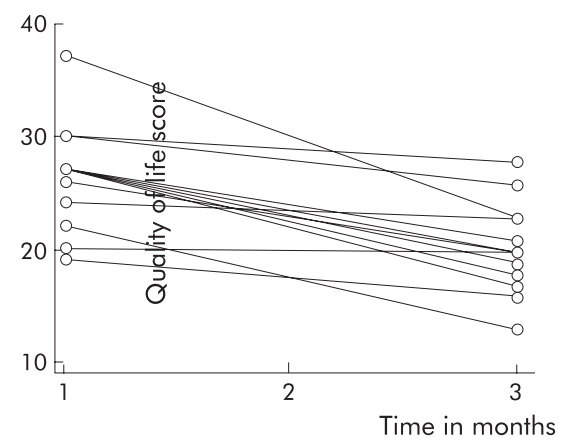

B

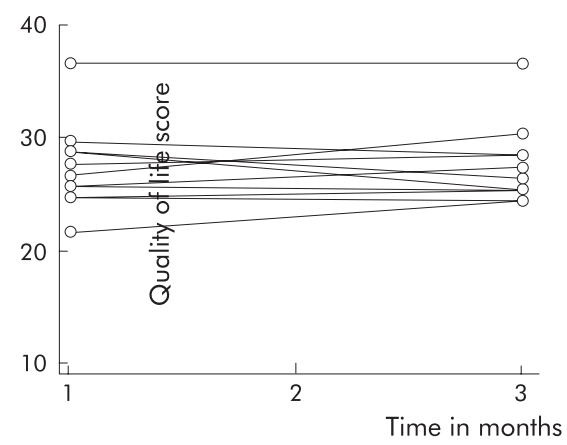

Figure 1 Asthma symptom scores (North of England asthma symptom scale) in (A) the intervention group and (B) the control group at baseline and 3 months later. Difference at 3 months adjusted for baseline scores $=7.0(95 \% \mathrm{Cl} 4.4$ to 9.5$), \mathrm{F}=21.4, \mathrm{p}<0.001$.

or negative. In a small randomised trial, Hayward and colleagues found a benefit of education in primary care after excluding from the analysis a participant whose asthma had worsened. ${ }^{7}$ In a larger study Thoonen and colleagues found no changes in quality of life, lung function, or exacerbation rates but did find an improvement in an unvalidated symptom score. ${ }^{8}$ Other studies have been negative ${ }^{6}{ }^{10}$ due to factors which may include inadequate intensity of the educational intervention or the relatively mild morbidity experienced by those recruited in primary care compared with the morbidity of those recruited in secondary care. More work is needed to show that education for the self-management of asthma, delivered in primary care by non-specialists, can reduce unscheduled care or exacerbation rates, perhaps by targeting more accurately those who are likely to benefit.

We specifically excluded from entry to our study subjects who had been admitted to hospital or seen in an accident and emergency department with asthma. This is important since, to date, most studies of self-management have comprised people recruited in secondary care.

The weaknesses of our study are its size, the lack of blinding to allocation of the pharmacist, and the lack of outcome measures other than a validated health status scale. Despite these weaknesses, the consistency of the results across the two study groups suggests that a community pharmacist can have an important impact on the asthma control of subjects who attend to receive dispensed medication. Our study was conceived as a pilot to demonstrate feasibility and determine size of effect for a larger study. Despite the lack of a prior power calculation, it seems reasonable to test for statistical significance. The finding of a mean change in symptom score of 6 points in participants receiving self-management advice suggests that these results are of clinical as well as statistical significance. ${ }^{14}$ While symptom scores could be argued to be the most important measure for individuals with asthma, our study could have been strengthened by the inclusion of other outcomes such as health service use or peak flow diaries. Such measures might give added information about the clinical relevance of our findings. However, much larger numbers of participants would be required before significant changes in health service use could be detected. Peak flow diaries could have been included but have two disadvantages. Firstly, our experience is that individuals from deprived backgrounds in east London are poor at completing peak flow charts. Secondly, asking control participants to complete diaries might have biased the study by providing feedback on asthma control.

Recent work has suggested that the impact of management and education for asthma is maximised when the clinician develops an ongoing partnership with the patient. ${ }^{13}{ }^{19}$ Our study supports this view: regular contact by the pharmacist over a period of months probably developed trust and confidence among the participants receiving the intervention.

Should community pharmacists routinely provide asthma self-management advice? While our small study is promising in this respect, there remain at least four important unresolved issues: (1) most community pharmacies have inadequate facilities for private consultation; (2) few pharmacists have received training in the delivery of asthma self-care advice; (3) it is unknown if improvements such as we found persist over time; and (4) with an increasing variety of healthcare professionals potentially involved in care, mechanisms are needed to ensure consistency of advice to patients.

Further studies should attempt to confirm our findings and address these unresolved issues using an intervention carefully integrated with other caregivers such as general practice, larger samples, a wider range of outcome measures, and longer follow up.

\section{Authors' affiliations}

D Barbanel, S Eldridge, C Griffiths, Institute of Community Health Sciences, Barts and the London, Queen Mary's School of Medicine and Dentistry, London El 4NS, UK

\section{REFERENCES}

1 Gibson PG, Powell H, Coughlan J, et al. Self-management education and regular practitioner review for adults with asthma (Cochrane Review). The Cochrane Library, Issue 1. Oxford: Update Software, 2003:1-47.

2 British Thoracic Society, Scottish Intercollegiate Guidelines Network. British guideline on the management of asthma. Thorax 2003;58(Suppl I):i1-94.

3 Bernsten C, Bjorkman I, Caramona M, et al. Improving the well-being of elderly patients via community pharmacy-based provision of pharmaceutical care: a multicentre study in seven European countries. Drugs Aging 2001; 18:63-77.

4 Charlton I, Charlton G, Broomfield J, et al. Evaluation of peak flow and symptoms only self management plans for control of asthma in general practice. BMJ 1990:301:1355-9.

5 Moudgil H, Marshall T, Honeybourne D. Asthma education and quality of life in the community: a randomised controlled study to evaluate the impact on white European and Indian subcontinent ethnic groups from socioeconomically deprived areas in Birmingham, UK. Thorax 2000:55:177-83.

6 Heard AR, Richards IJ, Alpers JH, et al. Randomised controlled trial of general practice based asthma clinics. Med J Aust 1999;171:68-71.

7 Hayward SA, Jordan M, Golden G, et al. A randomised controlled evaluation of asthma self management in general practice. Asthma Gen Pract 1996;4:11-3.

8 Thoonen BPA, Schermer TRJ, van den Boom G, et al. Self-management of asthma in general practice, asthma control and quality of life: a randomised controlled trial. Thorax 2003:58:30-6.

9 Hilton S, Sibbald B, Anderson HR, et al. Controlled evaluation of the effects of patient education on asthma morbidity in general practice. Lancet 1986;1:26-9

10 Jones KP, Mullee MA, Middleton M, et al. Peak flow based asthma self-management: a randomised controlled study in general 
practice. British Thoracic Society Research Committee. Thorax 1995;50:851-7.

11 Jones A, Pill R, Adams S. Qualitative study of views of health professionals and patients on guided self management plans for asthma. BMJ 2000:321:1507-10.

12 East London and the City Health Authority. Health in the East End. London: East London and the City Health Authority, 2002.

13 Griffiths C, Kaur G, Gantley M, et al. Influences on hospital admission for asthma in south Asian and white adults: qualitative interview study. BMJ 2001;323:962.

14 Steen N, Hutchinson A, McColl E, et al. Development of a symptom based outcome measure for asthma. BMJ 1994;309:1065-8.

15 Eccles M, McColl E, Steen N, et al. Effect of computerised evidence based guidelines on management of asthma and angina in adults in primary care: cluster randomised controlled trial. $B M J$ 2002;325:941.

16 Trinder PM, Croft PR, Lewis M. Social class, smoking and the severity of respiratory symptoms in the general population. J Epidemiol Community Health 2000:54:340-3.

17 Alvarez Puebla MJ, Castillo R, Rey A, et al. Sputum eosinophilia and maximal airway narrowing in Dermatophagoides pteronyssinus allergic rhinitis patients: only rhinitis or rhinitis plus mild asthma? Chest 2002; 122: 1560-5.

18 Herborg H, Soendergaard B, Froekjaer B, et al. Improving drug therapy for patients with asthma--part 1: Patient outcomes. J Am Pharm Assoc 2001;41:539-50

19 Clark NM, Gong M, Schork MA, et al. Impact of education for physicians on patient outcomes. Pediatrics 1998;101:831-6.

\section{LUNG ALERT}

Allergen impermeable covers appear clinically ineffective in the management of adult asthma patients

$\Delta$ Woodcock A, Forster L, Mattehews E, et al. Control of exposure to mite allergen and allergen-impermeable bed covers for adults with asthma. N Engl J Med 2003;349:3

$\mathrm{T}$

his double blind, randomised study compared allergen impermeable bed covers with

placebo covers in 1122 adults with asthma taking regular inhaled corticosteroids. The

primary outcomes were mean morning peak expiratory flow rate (PEFR) at 6 months and the proportion of patients who discontinued corticosteroid treatment as part of a phased reduction programme during months $7-12$. The mean morning PEFR improved significantly in both groups (from 410.7 to $419.1 \mathrm{l} / \mathrm{min}$ in the active intervention group, $\mathrm{p}<0.001$; and from 417.8 to $427.4 \mathrm{l} / \mathrm{min}$ in the control group, $\mathrm{p}<0.001)$. After adjustment for baseline differences (by analysis of covariance), there was no significant difference in the mean morning PEFR between the groups. Analysis of the proportion of patients in whom complete cessation of inhaled corticosteroids was achieved showed no significant difference between the groups ( $17.4 \%$ in the active intervention group and $17.1 \%$ in the control group).

This study shows that allergen impermeable covers, as a single intervention for the avoidance of dust mite allergen, appear to be clinically ineffective in adults with asthma.

M Belton

Senior House Officer, The Whittington Hospital, London; mbelton@doctors.net 